\title{
Attitudes and Motivations Following Shortened 2020 Season among NCAA Division II and Division III Baseball Players: A Pilot Study
}

ISSN: 2577-1914

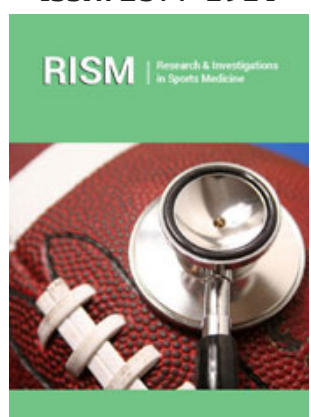

*Corresponding author: S Andrew C, University of Texas at Tyler, Texas, USA

Submission: 些April 14, 2020

Published: 㭗April 28, 2020

Volume 6 - Issue 3

How to cite this article: $S$ Andrew $C^{*}$, Brandon W, Diana G, Lynzi W, et al. Attitudes and Motivations Following Shortened 2020 Season among NCAA Division II and Division III Baseball Players: A Pilot Study. Res Inves Sports Med, 6(3): RISM.000637. 2020. DOI: $10.31031 /$ RISM.2020.06.000637

Copyright@ S Andrew C, This article is distributed under the terms of the Creative Commons Attribution 4.0 International License, which permits unrestricted use and redistribution provided that the original author and source are credited.

\author{
S Andrew $\mathrm{C}^{1 *}$, Brandon $\mathrm{W}^{2}$, Diana $\mathrm{G}^{1}$, Lynzi $\mathrm{W}^{3}$, Laurel $\mathrm{T}^{4}$, Julie $\mathrm{G}^{5}$ and Brent $\mathrm{P}^{1}$ \\ ${ }^{1}$ University of Texas at Tyler, USA \\ ${ }^{2}$ Grand Canyon University, USA \\ ${ }^{3}$ MVP Orthopedics, USA \\ ${ }^{4}$ Christus Trinity Mother Frances, USA \\ ${ }^{5}$ Collin College, USA
}

\begin{abstract}
In response to the global spread of severe acute respiratory syndrome coronavirus 2 (SARS-CoV-2), the National Collegiate Athletic Association (NCAA) cancelled all 2020 winter and spring championships that had not been completed. As a result of this cancellation and increasing travel restrictions, many conferences and institutions elected to cancel the remainder of their regular seasons for the 2019-2020 academic year. In response to these cancellations, the NCAA voted in favor of granting student-athletes who participated in spring sports and met certain criteria an extra year of eligibility. Currently, research is being conducted to evaluate the epidemiology, recognition, treatment and prevention of coronavirus disease 2019 (COVID-19), the disease associated with SARS-CoV-2. However, there does not appear to be any published research on the attitudes and motivations of NCAA spring sport student-athletes following the cancellations of their seasons and subsequent issuance of an extra year of eligibility. Therefore, the purpose of this pilot study is to describe the attitudes and motivations of collegiate baseball players at an NCAA Division II and NCAA Division III institution. A total of 47 collegiate baseball players participated in this study (Division II = 28; Division III = 19). Participants were sent an electronic survey via email that collected demographic information and assessed attitudes and motivations regarding the shortened season and extra year of eligibility. Data was downloaded and analyzed using a commercially available statistics package (SPSS Version 26, IBM, Armonk, NY). The overwhelming majority of collegiate baseball players surveyed in this pilot studied were disappointed and/or angry about the 2020 season being shortened (Disappointed $=100 \%$; Angry $=61.7 \%$ ). Of the baseball players who were going to be out of eligibility before the NCAA decision, $33.33 \%(n=7)$ stated they intended to make use of their additional year of participation. Additionally, the majority of baseball players reported they were more excited about next season as a result of this season being shortened $(74.47 \%, \mathrm{n}=35)$. Between the two groups, there were not significant differences with regards to attitudes toward the shortened season. However, more Division III baseball players cited graduation and job offers as reasons they would not be using their additional year of eligibility. This pilot study serves as validation for a larger scale study on multiple NCAA baseball teams to determine the overarching attitudes and motivations following the shortened 2020 season.
\end{abstract}

\section{Introduction}

Coronavirus disease 19 (COVID-19) is a serious respiratory disease caused by severe acute respiratory syndrome coronavirus 2 (SARS-CoV-2) [1]. COVID-19 was first detected in December, 2019 in Wuhan, China [1]. The disease has been found to be highly infectious, and features symptoms including: fever, dry cough, fatigue, muscle and joint pain, and shortness of breath [1]. In severe cases, patients have been reported as developing pneumonia, septic shock, metabolic acidosis, and coagulation dysfunction [2]. In the absence of a proven treatment or vaccine, the primary means of mitigating the spread of COVID-19 has been social distancing, recognition through testing, and enhanced hygiene precautions $[3,4]$. 
As the COVID-19 outbreak spread, more communities and organizations began making decisions in an attempt to slow the spread of COVID-19. To this end, the NCAA chose to cancel all remaining spring and winter championships [5]. After this decision was made, the majority of institutions and conferences chose to cancel the remainder of their seasons [6]. Given that studentathletes competing in spring sports had the majority of their seasons ended prematurely due to these cancellations, the NCAA voted to provide student-athletes meeting certain criteria with an extra year of eligibility [7].

Currently, research is being conducted to evaluate the epidemiology, recognition, treatment and prevention of COVID-19 [1-4]. However, there does not appear to be any published research on the attitudes and motivations of NCAA spring sport studentathletes following the cancellations of their seasons and subsequent issuance of an extra year of eligibility. Therefore, the purpose of this pilot study is to describe the attitudes and motivations of collegiate baseball players at an NCAA Division II and NCAA Division III institution.

\section{Methods}

\section{Design}

This study was conducted using a cross-sectional design utilizing an internet-based survey for data collection.

\section{Participants}

Participants were recruited for this study by emailing the head baseball coaches at two NCAA institutions. Institution A is a public university in the southern United States of America that competes in the NCAA Division II. Institution B is a private university in the southern United States of America that competes in the NCAA Division III. The coaches of the respective institutions forwarded an email to their teams that invited them to participate in the electronic survey. A total of 69 baseball players were emailed (Institution A = 34; Institution $B=35$ ). 47 participants (Institution $A=28,20.9 \pm$ 1.3 years; Institution $B=19,20.1 \pm 1.5$ years) opened the survey link and completed the instrument (access and completion rates $=68 \%$ ). All participants were informed of the survey's purpose as part of the beginning of the survey, at which point informed consent was obtained.

\section{Data collection}

An email was sent to the head coaches of the baseball teams recruited for this pilot study requesting that they send an invitation written by the investigators to their rosters. The message was then forwarded to all prospective participants inviting them to participate in an electronic survey via a hyperlink from a web-based server (Qualtrics Inc., Provo, UT) from March to April 2020. The inviting message contained information about the investigators, the purpose of the study, the nature of the survey, and assurances that the participants could opt to not complete the survey at any time. A follow-up email was sent a week after the initial email, and left open for a week prior to the survey being closed for statistical analysis.

\section{Instrument}

Following the informed consent and demographics section, the instrument contained items related to the academic classification, NCAA athletic classification, and playing position. Other items gathered information on the attitudes of participants toward the shortened 2020 season, intentions to utilize the extra year of eligibility being granted, and motivations to perform well the following season. Participants were also asked open ended questions regarding their personal reasons for using their extra year of eligibility or not.

The survey consisted of 18 total questions. These questions included: one question regarding consent to participate in the study, one fill in the blank and three multiple questions regarding demographic information, 10 multiple choice questions regarding attitudes, motivations, and intentions towards the shortened 2020 season and extra year of eligibility, and four open ended questions regarding the participants' personal reasons for using their extra year of eligibility or not.

\section{Statistical analysis}

Information from participant responses was downloaded and analyzed using a commercially-available statistics package (SPSS Version 26, IBM, Armonk, NY). Of the 69 collegiate baseball players who received the survey, 47 completed responses were included in the data analysis. Measures of central tendency (means, standard deviations, frequencies) were calculated where appropriate. Independent samples t-tests were used to compare the responses of the participants from Institution A and Institution B.

\section{Results}

\section{Attitudes toward the shortened 2020 season}

The majority of responding collegiate baseball players felt disappointed upon receiving the news that the 2020 season had been ended prematurely $(97.9 \%, n=46)$. Additionally, the majority of respondents also felt angry upon receiving the news that the 2020 season had been prematurely ended $(61.7 \%, n=29)$. More respondents reported feeling disappointed about the shortened season rather than angry. Independent samples t-tests revealed there were no significant differences in the emotions experienced by respondents from the different institutions ( $p>.05$ ). Table 1 provides a breakdown of the questions that gathered information on respondents' attitudes toward the shortened 2020 baseball season. 
Table 1: Responses for questions on the emotions and attitudes experienced upon learning that the 2020 baseball season would be cancelled.

\begin{tabular}{|c|c|c|c|}
\hline \multirow{2}{*}{ Attitude/Emotion } & \multicolumn{3}{|c|}{ Most Common Responses (\%) } \\
\hline & Institution $A(n=28)$ & Institution B (n=19) & Total $(n=47)$ \\
\hline \multirow{2}{*}{ Surprised } & Strongly Agree, 8 (28.57\%) & Agree, 7 (36.84\%) & Agree, $18(38.30 \%)$ \\
\hline & Agree, $10(35.71 \%)$ & Strongly Agree, 4 (21.05\%) & Strongly Agree, 12 (25.53\%) \\
\hline \multirow{2}{*}{ Stunned } & Agree, 14 (50\%) & Agree, 8 (42.11\%) & Agree, 22 (46.81\%) \\
\hline & Strongly Agree, 11 (39.29\%) & Somewhat Agree, 5 (26.32\%) & Strongly Agree, 15 (31.91\%) \\
\hline \multirow{2}{*}{ Excited } & Strongly Disagree, 22 (78.6\%) & Strongly Disagree, 12 (63.2\%) & Strongly Disagree, 34 (72.3\%) \\
\hline & Disagree, $3(10.7 \%)$ & Disagree, $6(31.6 \%)$ & Disagree, $9(19.2 \%)$ \\
\hline \multirow{2}{*}{ Happy } & Strongly Disagree, 24 (85.7\%) & Strongly Disagree, 13 (68.4\%) & Strongly Disagree, 37 (78.7\%) \\
\hline & Disagree, 3 (10.7\%) & Disagree, 5 (26.3\%) & Disagree, 8 (17\%) \\
\hline \multirow{2}{*}{ Disappointed } & Strongly Agree, 20 (71.4\%) & Strongly Agree, 12 (63.2\%) & Strongly Agree, 32 (68.1\%) \\
\hline & Agree, 7 (25\%) & Agree, $6(31.6 \%)$ & Agree, $13(27.7 \%)$ \\
\hline \multirow{2}{*}{ Angry } & Agree, 6 (21.4\%) & Somewhat Agree, 7 (36.8\%) & Somewhat Agree $13,(27.7 \%)$ \\
\hline & Neither Agree nor Disagree, 7 (25\%) & Strongly Agree, 4 (21.1\%) & Strongly Agree, 10 (21.3\%) \\
\hline
\end{tabular}

\section{Motivations for coming seasons}

Out of the respondents who were going to be out of eligibility, $33.33 \%$ reported intentions to utilize their additional year of eligibility $(n=7)$. Furthermore, the majority of respondents reported being more excited for the 2021 season as a result of the 2020 season being shortened $(74.47 \%, n=35)$. When asked for the primary reason to use the extra year of eligibility, common themes that emerged included a chance to continue playing, a chance to prove their ability, and the need to complete an extra year of school. When asked for the primary reason to not use the extra year or eligibility, common themes that emerged included the cost of school, graduation, and obtaining employment. Table 2 provides a breakdown of these themes.

Table 2: Themes of responses to open ended questions regarding the decision on whether or not to use extra year of eligibility.

\begin{tabular}{|c|c|}
\hline Question & Most Common Responses (\%) \\
\hline $\begin{array}{c}\text { Why would you choose to use } \\
\text { your extra year of eligibility? }\end{array}$ & $\begin{array}{c}\text { Chance to continue playing, 30 (63.8\%) } \\
\text { Additional classes to take, 9 (19.1\%) } \\
\text { Chance to prove my ability, 3 (6.4\%) }\end{array}$ \\
\hline $\begin{array}{c}\text { Why would you choose to } \\
\text { NOT use your extra year of } \\
\text { eligibility? }\end{array}$ & $\begin{array}{c}\text { Job offer, } 10(21.3 \%) \\
\text { Graduation, 8 }(17 \%)\end{array}$ \\
\hline
\end{tabular}

\section{Discussion}

The purpose of this pilot study was to describe the attitudes, motivations, and intentions of collegiate baseball players whose 2020 seasons had been shortened due to the COVID-19 pandemic. A secondary purpose was to assess any differences in these variables between NCAA Division II and NCAA Division III baseball players. Our findings suggest that the majority of respondents surveyed were disappointed $(97.9 \%, \mathrm{n}=46)$ and/or angry $(61.7 \%, \mathrm{n}=29)$ that the 2020 season was cancelled. Interestingly, more respondents reported being disappointed rather than angry. When compared to one another, there were no significant differences in attitudes toward the shortened season between NCAA Division II and NCAA Division III baseball players ( $\mathrm{p}>$.05). This suggests that the division a baseball player was competing in did not have an effect on their attitudes toward their season being shortened.

For respondents who were going to be out of eligibility, only $33.33 \%(n=7)$ reported that they would use their additional year of eligibility. The main factors for choosing not to use the extra year of eligibility appeared to be related to graduation, employment opportunities, and the cost of continuing to attend school. This suggests that factors other than baseball were the primary reasons for respondents to forego the extra year of eligibility they had been granted.

A possible limitation of this study was the relatively low number of participants. While the response rate for the survey was high (68\%), a definitive statement on the attitudes, motivations, and intentions of collegiate baseball players following the shortened 2020 season would require a larger scale study. However, the completion of this pilot study provides a framework for conducting a study that collects data from a larger number of institutions and respondents.

There is a need for additional research into the attitudes, motivations, and intentions of all spring sport student-athletes in the NCAA following the shortened 2020 season. The cancellation of a spring season of sports in the NCAA is unprecedented, and as such requires examination of all potential implications. Future research could also be conducted on the role that identifying as a student or an athlete may have on respondents' attitudes, motivations, and intentions following the shortened 2020 season. 


\section{Conclusion}

In conclusion, the majority of surveyed collegiate baseball players were disappointed and/or angry about the 2020 season being cancelled. In spite of these negative emotions, less than half of respondents who were due to be out of eligibility expressed the intent to utilize the additional year of eligibility that has been granted. As athletic trainers, coaches, and administrators move forward it is important to consider all possible implications of spring sport student-athletes in the NCAA having a season cancelled. Consideration of these details may provide the opportunity to intervene should student-athletes experience particularly negative emotions or decreases in motivation.

\section{References}

1. Zhong BL, Luo W, Mei LH, Zhang QQ Liu XG, et al. (2020) Knowledge, attitudes, and practices toward COVID-19 among Chinese residents during the rapid rise period of the COVID-19 outbreak: A quick online cross-sectional survey. International Journal of Biological Sciences 16(10): 1745-1752.

2. Chen N, Zhou M, Dong X, Qu J, Gong F, et al. (2020) Epidemiological and clinical characteristics of 99 cases of 2019 novel coronavirus pneumonia in Wuhan, China: A descriptive study. Lancet 395(10223): 507-513.

3. Patel R, Babady E, Theel ES, Storch GA, Pinsky BA, et al (2020) Report from the american society for microbiology COVID-19 International Summit, 23 March 2020: Value of diagnostic testing for SARS-CoV-2/ COVID-19. mBio 11(2).

4. Ebrahim SH, Memish ZA (2020) COVID-19 - The role of mass gatherings. Travel Medicine and Infectious Disease.

5. ESPN (2020) Coronavirus cancellations and reactions in sport.

6. ESPN (2020) SEC becomes latest conference to cancel sports for 20192020.

7. ESPN (2020) NCAA approves extra year of eligibility for spring athletes. 